INTERNATIONAL JOURNAL OF SYSTEMATIC BACTERIOLOGY

Vol. 18, No. 1 January 1968

pp. $51-66$

Copyright 1968, Iowa State University Press

\title{
PROPOSAL FOR THE RECOGNITION OF TWO SPECIES \\ IN THE GENUS CHLAMYDIA JONES, RAKE, AND STEARNS, $1945^{1}$
}

\section{A. Page ${ }^{2}$}

National Animal Disease Laboratory, Animal Disease and Parasite Research Division, Agricultural Research Service, United States Department of Agriculture, Ames, Iowa

ABSTRACT. The bacteria which cause the psittacosis-trachoma group of diseases and which are assigned to the genus Chlamydia Jones, Rake, and Stearns, 1945, can be separated conveniently and logically into two species. This separation is based on relatively stable morphological and chemical characteristics of the organisms rather than on their presumed host or tissue preferences or on the specific serology of their cell wall antigens. The type species Chlamydia trachomatis (Busacca) Rake 1957 is differentiated from the second species Chlamydia psittaci (Lillie 1930 ) comb. nov., by a simple key using tests that can be performed readily in the laboratory. Each species is defined, and the laboratory tests are described.

\section{INT RODUCTION}

In 1965 it was apparent that the numerous taxonomic and nomenclatural proposals made over two decades by American, Russian, and French workers had failed to stabilize the scientific naming of the group of related organisms that cause psittacosis, trachoma, and other diseases. Prior to

This proposal has been reviewed and approved by a majority of the members of the Subcommittee on the Chlamydiaceae, Taxonomy Committee, American Society for Microbiology, October 1967.

2 Secretary, Subcommittee on the Chlamydiaceae, Taxonomy Committee, American Society for Microbiology. 
1965. American systematists adhered to Rake's placement of these organisms into two genera, Chlamydia Rake 1956 and Miyagawanella Brumpt 1938, although many workers favored,forhistoric and phonetic reasons the generic name Bedsonia, which was belatedly proposed by Meyer (1953). Intervening were the validly published proposals of Moshkovsky (1945), Ryzhkov(1950), Zhdanov and Korenblit (1950), and Zhdanov(1953) of the genus names Chlamydozoon for the organisms causing trachoma and Ehrlichia or Rickettsiaformis for the organisms causing psittacosis. The Russian authors considered them to be viruses. Lastly, Levaditi, Roger, and Destombes proposed in 1964 that these organisms be split among four genera: Chlamydia Rake, Miyagawanella Brumpt, Bedsonia Meyer, and Rakeia Levaditi et al.

The questions raised by these various proposals were examined for taxonomic merit in the light of recent chlamydial research, and evaluated according to the International Code of Nomenclature of Bacteria (1958) for nomenclatural legitimacy (Page 1966). The conclusions of this study, reached after consultation with American systematists and microbiologists, ${ }^{1}$ were:

(1) That the evidence accumulated by Moulder $(1964,1966)$ and others established that the etiologicagents of trachoma, psittacosis, and related diseases were procaryotic microorganisms, or bacteria in the broad sense, and were fundamentally distinct from the viruses.

(2) That the characteristics used to unite these organisms into a single genus (morphology, developmental cycle, and group antigen) were of greater taxonomic significance than the characteristics used to separate them into two or four genera (presumed host or tissue preferences on the part of the organisms, and patronymics on the part of historyminded humans). Therefore, it was appropriate to classify the group of organisms into one genus.

(3) That, according to the rules of the International Code of Nomenclature of Bacteria, the earliest validly published, legitimate and correct name for this genus was Chlamydia, Jones, Rake and Stearns, 1945. These authors also were the first to express the concept that all of the agents causing either trachoma, psittacosis or related diseases were members of a single genus. All other generic names for chlamydiae either were invalidly published or were later synonyms of Chlamydia.

R. E. Buchanan, C. B. Philip, J.W. Moulder, F. B. Gordon, E. Jawetz, and M. Pollard. 
The publication by Page (1966) did not propose any new names, but it clarified the taxonomic and nomenclatural position of previously proposed names and emphasized the correct scientific name. Its purpose was to simplify and to stabilize chlamydial nomenclature.

\section{Reasons for the Recognition at Present of Two Species in the Genus Chlamydia}

In the past, classification systems proposed for chlamydiae have used presumed tissue or host affinities of the organisms as heavily weighted taxonomic criteria. This is understandable because less was known about the organisms themselves than about the damage they caused to their hosts. Moshkovsky (1945) emphasized host cell origin and introduced the terms "mesodermosis". for psittacosis, lymphogranuloma venereum, and a number of other diseases, and "ectodermosis" for trachoma and various conjunctival inflammations. He classified the etiologic agents of these diseases on the basis of their presumed tissue cell affinities. The classification system of Rake in Bergey's 6th (1948) and 7th (1957) editions also reflected a tissue-affinity/ host preference outlook. Examples are:

Disease

Trachoma

Inclusion conjunctivitis

Lymphogranuloma venereum

Psittacosis
Psittacosis in non-
$\quad$ psittacine birds
Enzootic abortion in ewes
Sporadic bovine
$\quad$ encephalomyelitis
Calf enteritis

Specific etiology

Chlamydia trachomatis

Chlamydia oculogenitale

Miyagawanella

lymphogranulomatosis

Miyagawanella psittaci

Miyagawanella ornithosis Miyagawanella ovis

Miyagawanella pecoris Miyagawanella bovis

On the other hand, Levaditi et al. (1964) suggested that these organisms should be separated on the basis of a presumedly unique epidemiology. Thus, the agents associated with trachoma belonged in the genus Chlamydia, with lymphogranuloma venereum in Miyagawanella, with psittacosis in birds and man in Bedsonia, and with diseases of domestic herbivores in Rakeia. 
In the light of recent evidence, the use of such criteria in the classification of chlamydiae is contraindicated; for, when knowledge of the clinical syndrome of the host is not available, Chlamydia trachomatis in Rake's schema cannot be satisfactorily distinguished by laboratory tests from Chlamydia oculogenitale or from Miyagawanella lymphogranulomatosis. If the organisms are isolated from the genital tract of a person with no evidence of disease, they cannot be assigned with certainty to any of Rake's species. Dunlop and his colleagues (1966) recently reported the isolation of chlamydiae from the urogenital tracts and conjunctiva of patients with clinical urethritis, opththalmia neonatorum, or trachoma. All of the isolates were microbiologically indistinguishable. These authors stated that there was "no difference between the isolate from the eye and that from the genital tract in each case." In anothe $r$ case, these authors reported that "an isolate of what is probably a TRIC* agent has been obtained from the rectum of a woman with ocular infection due to the agent.... The difficulty in differentiating such cases from lymphogranuloma venereum (LGV), and TRIC agent from the agent of LGV, is apparent."

Other examples illustrate the inadvisability of ascribing a species designation to a strain of organisms presumed to be the sole cause of a particular disease. Schachter (1967) reported the isolation from the tissue of a patient with clinical lymphogranuloma venereum of an organism that was morphologically, pathogenically, and chemically indistinguishable from strains normally recovered from psittacine birds. Was the patient with clinical LGV infected with Miyagawanella lymphogranulomatosis or with $\underline{M}$. psittaci?

Page (1967) reported that a chlamydial agent implicated in a case of bovine enteritis and in a case of fatal psittacosis was identical in "pathotype" and morphological and chemical characteristics to a strain typical of those frequently recovered from pigeons. However, it was quite different from another strain which had caused an epizootic of bovine abortions. Were the bovines and the human subject infected with M. psittaci, M. ornithosis, $\underline{M}$. bovis, or $\underline{M}$. pecoris? Was the patient who was affected by the bovine agent suffering from psittacosis, ornithosis, or mammalosis?

Unfortunately, serotyping of the strains isolated from various hosts with differing disease syndromes has not re-

* TRIC = TRachoma Inclusion Conjunctivitis. 
solved the difficulties. While numerous serotypes can be distinguished on the basis of the specificity of cell wall antigens by using toxin-antitoxin reactions, growth-inhibition in tissue culture, or complement fixation tests, this approach has failed to produce a pattern suitable for taxonomic classification (Fraser and Berman 1965). Past experience indicates that specific serology as a basis for species separation leads to long lists of names which assist epidemiology but detract from taxonomy, especially when embarrassing cross reactions occur. DNA homology tests also have not aided clsssification because of the high degree of homology between the DNA's of different strains (Gerloff et al. 1966).

A solution to this nomenclatural and taxonomic dilemma was suggested by the work of Gordon and Quan (1965) who reported that a number of chlamydial strains recovered from a variety of diseased tissues and hosts could be separated into two major groups on the basis of morphological and chemical characteristics of the organisms alone. Gordon and Quan observed (as had others previously) that organisms associated with trachoma, inclusion conjunctivitis, lymphogranuloma venereum, and mouse pneumonitis developed compact intracytoplasmic microcolonies (inclusions in tissue cells) which produced sufficient quantities of glycogen detectable by staining with iodine solution. Lin and Moulder (1966) confirmed these observations and added another apparently stable characteristic. They found that the multiplication in chicken embryos of the chlamydiae that formed compact microcolonies and produced glycogen was inhibited by sodium sulfadiazine. The strains in the nonglycogen producing, sulfadiazine, resistant group were organisms frequently associated with psittacosis, meningopneumonitis, guinea pig conjunctivitis, bovine encephalomyelitis, feline pneumonitis, or caprine pneumonitis.

These morphological and chemical characteristics were tested recently and confirmed by the author for a group of 15 strains of chlamydiae isolated from man, turkeys, a pigeon, a sparrow, parakeets, a gull, a mouse, cattle, sheep and a muskrat. Representative strains from both biological groups mentioned by Gordon and Quan were also tested. All strains fit the expected pattern (save the well known "6BC" parakeet strain which is glycogen negative but sensitive to sulfadiazine) and were readily separated into one or the other major group (Page 1967, unpublished observations).

The results of Gordon and Quan and Lin and Moulder established the first natural grouping of these organisms based 
on relatively stable morphological and chemical characteristics of the organisms themselves, rather than on variable responses of animal hosts to infection or on a multitude of specific cell wall antigens. Moreover, the characteristics used are ones that are subject to test in any laboratory equipped to isolate and study chlamydiae. These are conditions that greatly assist the task of taxonomy.

It is expected that other relatively stable characteristics of chlamydiae will be recognized and utilized to substantiate either the present dichotomous grouping or to justify the introduction of new groupings. Such is the dynamism and flexibility of taxonomy.

Therefore, it is proposed that two species be recognized for the organisms of the genus Chlamydia (Jones, Rake and Stearns 1945) which include the causative agents of trachoma, psittacosis and related diseases. These two species are Chlamydia trachomatis (Busacca) Rake 1957, which is the previously established type species, and Chlamydia psittaci (Lillie) comb. nov. A definition of the genus and of each species, a simple key for the differentiation of the species, and an explanation of the laboratory tests used for the differentiation, follow.

\section{GENERAL LIMITS OF THE ORGANISMS IN THE GENUS CHLAMYDIA JONES, RAKE AND STEARNS 1945}

Morphology and Mode of Reproduction. The organisms are spheroidal, bounded by a rigid cell wall when mature, and nonmotile. They have a unique, obligately intracellular developmental cycle characterized by the change of the primary infectious organism in the cytoplasm of the host cell to a reticulate thin walled spheroid, $0.9-1.0 \mu$ in diameter, which divides by fission. Division continues, while some daughter cells gradually reduce in size to become dense spherules, $0.3 \mu$ in diamete $r$, which are the final infectious form of the organism. Intracytoplasmic microcolonies, or plaques, $2-12 \mu$ in diameter, may contain all stages of initial, intermediate, and mature forms of the organism. The organisms can be separated into two groups based on whether the microcolony is rigid and compact, or whether it is diffused throughout the host cell's cytoplasm. When the host cell is damaged, the infectious spherules are released to repeat the cycle in other host cells, although secondary microcolonies may be established in a single host cell. 
Chemistry of the Organisms. Both deoxyribo- and ribonucleic acids have been demonstrated in the organisms at all stages of growth. Their cell walls are similar in general chemical composition to those of Gram-negative bacteria. The organisms have a negative Gram reaction and stain readily by Giemsa's, Macchiavello's, or Castenada's methods. Strains that form compact microcolonies characteristically produce glycogen that is demonstrable by staining the microcolony with a solution of iodine-potassium iodide. Strains that form diffuse microcolonies fail to produce detectable glycogen. Organisms of all strains have metabolic capabilities independent of the host cell, such as the catabolism of glucose to carbon dioxide when provided with essential inorganic and organic cofactors. The intracellular multiplication of organisms of every strain (except experimental mutants) is inhibited by tetracycline antibiotics. The multiplication of glycogen-producing strains is characteristically inhibited by sodium sulfadiazine. Every strain contains an antigenically similar lipo-protein-carbohydrate complex which is stable at $100^{\circ} \mathrm{C}$. Strain-specific antigens are found in the cell walls.

Natural Habitat and Cultivation. The organisms are parasites of tissue cells of vertebrates, although they may be found in or on ectoparasitic arachnids. They a re transmitted between vertebrate hosts by the inhalation of infectious excrements of birds and mammals, by contamination of conjunctiva or other mucous membrane with infectious urogeni tal exudates during birth or venereal contact. Intravenous transmission may take place mediated by sanguivorous arthropods. The organisms may produce generalized infections in a given host, but some strains localize and cause pronounced cellular changes in one or more tissues or organs, such as, the conjunctiva, eyes, lungs, liver, spleen, vascular endothelium, joints, urethra, vagina, lymph nodes, fetal and placental membranes, meninges, or brain. After appropriate adaptation, all of the strains may be propagated in the yolk sac of chicken embryos or in cultures of vertebrate tissues. To date, extracellular propagation of the organisms has not been achieved. 


\section{DEFINITION OF THE TYPE SPECIES AND ONE ADDITIONAL SPECIES IN THE GENUS CHLAMYDIA}

1. Chlamydia trachomatis (Busacca) Rake 1957, 958. (Rickettsia trachomae (sic) Busacca 1935, 567; Rickettsia trachomatis Foley and Parrot 1937, 230; Chlamydozoon trachomatis Moshkovsky 1945, 18; Chlamydozoon trachomiati (sic) Ryzhkov 1950, 17.)

The following species previously described in Bergey's 7th Edition and elsewhere are here considered putative synonyms of $\underline{\text {. }}$. trachomatis (Busacca) Rake:

Chlamydia oculogenitalis (Moshkovsky, 1945) Rake 1957;

Chlamydozoon oculogenitale Moshkovsky op. cit. ;

Miyagawanella lymphogranulomatosis, Brumpt, Ann. de Parasitol. 16, 1938, 155;

Ehrlichia (Miyagawanella) lymphogranulomatosis Moshkovsky, op. cit.;

Rickettsiaformis lymphogranulomatis Zhdanov and Korenblit, op. cit. ;

Chlamydozoon lymphophilus, Ryzhkov, op. cit.;

Miyagawanella bronchopneumoniae (Moshkovsky, 1945) Rake 1948, 1118;

Ehrlichia bronchopneumoniae Moshkovsky, op. cit.;

Cystidium bronchopneumoniae muris Ruska (Ruska and Poppe 1947);

Cystidium gonne rtianum, Ruska, op. cit. ;

Rickettsiaformis muris, Zhdanov and Korenblit, op. cit.; Chlamydozoon murinus Ryzhkov, op. cit.

tra. cho'ma.tis. Gr. n. trachoma roughness; M. L. n. trachoma trachoma; M. L. gen. n. trachomatis of trachoma.

Spheroidal, nonmotile organisms whose diameters range from 0.3 to $0.9 \mu$ depending upon their stage of development in an obligately intracellular multiplication cycle. During the first two to three days of growth, the organisms form rigid, compact intracytoplasmic microcolonies which may contain organisms in all stages of development. In time, several hundred mature infectious forms, which are small, dense spherules $0.3 \mu$ in diameter, may emerge from ruptured plaques to fill the host cell's cytoplasm. Secondary microcolonies may be formed. The spherules are released to infect other cells when the host cell is damaged. For a limited period (two or three days) glycogen is accumulated in the intracellular plaque in sufficient quantities to be 
demonstrable microscopically after fixing the infected host cells in methyl alcohol and then staining them with an alcoholic solution of 5\%.iodine-potassium iodide. The organisms are Gram-negative and can be readily seen microscopically after staining them by Giemsa's method. In cell cultures, the organisms may be seen without any staining if phase contrast optics are used.

Multiplication of the organisms in the yolk sac membrane of the chick embryo is inhibited at least one hundred fold by $1 \mathrm{mg}$ of sodium sulfadiazine. The degree of inhibition is determined by a dual titration of a suspension of organisms containing at least one million embryo lethal doses $50 \%$ per $\mathrm{ml}$ in chicken embryos by the yolk sac route in the presence and absence of $1 \mathrm{mg}$ of sodium sulfadiazine (inoculated separately into the yolk sac) per embryo. Intracellular multiplication of the organisms is inhibited by tetracycline also.

The organisms contain a lipo-protein-carbohydrate complex that is antigenically similar to a complex found in all strains of both species of the genus. The antigen is stable at $100^{\circ} \mathrm{C}$ and reacts with antibodies against any other strain to fix complement. Various serotypes, however, can be distinguished on the basis of the antigenic specificity of components of the organisms' cell walls.

The organisms are parasites of tissue cells of vertebrates and may be transmitted between vertebrate hosts, especially man, by transfer of ophthalmic or urogenital exudates from membranes of the susceptible host. Transmission occurs through various forms of contact contamination such as that of a fetus during birth or that of mucous membranes during venereal contact. In man, the organisms may localize in one or more tissues or organs and cause pronounced cellular changes in the conjunctiva, cornea, synovial membranes, urethra and adjoining lymph nodes, meninges, or brain. Strains of ic. trachomatis are usually responsible for various diseases or syndromes in man called trachoma, inclusion conjunctivitis, lymphogranuloma venereum, and may include arthritis and meningitis. One strain causes endemic pneumonitis in colonies of mice and is probably transmitted via the respiratory route.

The organisms may be isolated and propagated in the yolk sac of chicken embryos incubated at 35 to $37^{\circ} \mathrm{C}$. Serial blind passage of the culture in chicken embryos may be necessary before any effects on the embryo can be observed. Some strains have a stenothermal requirement growing only at $35^{\circ} \mathrm{C} \pm 1^{\circ} \mathrm{C}$. They may be propagated in cultures of ver- 
tebrate tissues. Strains that a re frequently associated with ophthalmic diseases of man may be propagated in the lungs of mice and guinea pigs, and the skin of guinea pigs. In subhuman primates they readily cause ophthalmic abnormalities and in some cases may disseminate throughout the body via the blood stream. Other strains can be propagated in the lungs or brains of young mice after inoculation by the appropriate route.

2. Chlamydia psittaci (Lillie) comb. nov.

(Rickettsia psittaci, Lillie, 1930,773; Microbacterium multiforme psittacosis, Levinthal, 1930,523; Ehrlichia psittaci Moshkovsky, 1956, 18; Rickettsiaformis psittacosis Zhdanov and Korenblit, 1950,43; Chlamydozoon psittaci Ryzhkov, 1950, 17.)

Herein considered as putative synonyms are:

Miyagawanella psittaci, M. ornithosis, M. pneumoniae, M. felis, $\underline{\text { M. louisianae, }}$ M. illinii, $\underline{\mathrm{M}}$. opossumi, $\underline{\mathrm{M}}$. ovis, $\underline{M}$. bovis, and $\underline{M}$. pecoris which Rake placed in the genus Miyagawanella in the 7th edition of Bergey's Manual (1957); Rickettsiaformis ornithosis, R. pneumoniae, R. meningopneumoniae, and R. felis, Zhdanov and Korenblit, op. cit., and $\underline{R}$. columbarum, R. opossum, R. bovis, R. ovis, Zhdanov, 1953; Chlamydozoon columbi, C. felis, C. meningophilus, ‥ cricetis, ‥ hominis, ‥ osteophilus, $\underline{\text { C. }}$

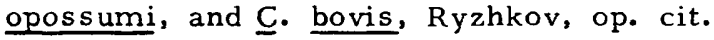

psit'ta.ci. Gr. n. psittacus a parrot; M. L. gen. n. psittaci of a parrot.

Spheroidal, nonmotile organisms, 0.3 to $1.0 \mu$ in diameter, resembling those of Chlamydia trachomatis. During the first day of obligate, intracellular growth, the organisms form loosely bound intracytoplasmic microcolonies which give the organisms the appearance of being distributed about cytoplasm of the host cell. In this respect they differ from Chlamydia trachomatis, but the mode of multiplication is the same. The microcolonies do not form any glycogen detectable by iodine staining. The organisms are Gram-negative and can be readily seen microscopically after staining by Giemsa's, Macchiavello's or Castenada's methods, or without staining if phase contrast optics are used.

Multiplication of the organisms in the yolk sac of chicken embryos is inhibited by tetracycline antibiotics but not by sodium sulfadiazine. 
The organisms contain a lipo-protein-carbohydrate complex that is antigenically similar to that found in all strains of Chlamydia. The antigen can be used to detect complement fixing antibodies to this complex stimulated by any other strain. Numerous serotypes, however, can be distinguished on the basis of the antigenic specificity of the components of the cell walls of the organisms. These antigens can be separated when reacted separately with homologous and heterologous antibodies in toxin protection tests in mice, growth inhibition tests in tissue cultures and complement fixation tests.

The organisms are parasites of tissue cells of vertebrates. They may be transmitted between vertebrate hosts by inhalation of aerosols of nasal or fecal excrements of infected birds or mammals, by various forms of contact contamination possibly including the bite of sanguivorous a rachnids, and by transovarian passage to the fetus in mammals. The organisms generally produce systemic infection in a broad range of avian and mammalian hosts, although some strains appear to have a narrow host spectrum. Respiratory transmission of the organisms is readily accomplished when a susceptible host inhales fine dust containing dried nasal or cloacal excrement of infected birds. This method has been responsible for epidemics of psittacosis in man and other animals. The organisms have been detected in over 100 species of wild and domestic birds, most domesticated animals, and in many wild mammals. Some of the diseases caused by various strains of Chlamydia psittaci have been described as: psittacosis, ornithosis, meningopneumonitis; feline, bovine, ovine, porcine, caprine, or human pneumonitis; opossum encephalitis; sporadic bovine encephalomyelitis; ovine, bovine, or porcine arthritis; epizootic bovine abortion; enzootic abortion of ewes; guinea pig conjunctivitis; fatal epizootic disease of hares and muskrats.

In generalized infections, the organisms may multiply initially in epithelial cells of several organs, especially the lowe $r$ respiratory tract, and then are distributed throughout the body via the blood stream. Damage to vascular endothelia causes spread of the organisms and plasma to the surfaces of many organs where fibrinous inflammatory exudates accumulate resulting in characteristic lesions. Common findings accompanying pneumonitis are pericarditis, perihepatitis, peritonitis, ascites, hepatomegaly, spl enomegaly, and other signs of generalized infection. The organisms cause 
a wide range of effects depending upon all of the classic factors affecting host-parasite relationships. Many hosts of various species become asymptomatic carriers of Chlamydia psittaci thereby perpetuating the organisms in nature. Some strains localize in certain tissues or organs of the host causing splenomegaly, or transient pneumonitis, arthritis, fetal or placental inflammation resulting in abortion.

The organisms are readily isolated and propagated in the yolk sacs of chicken embryos incubated at 37 to $40^{\circ} \mathrm{C}$. Many strains recovered from mammals with high normal body temperatures have optimal growth temperatures of $39^{\circ} \mathrm{C}$ or above. Most strains can be propagated in the lungs, brains, or peritoneal cavity of laboratory mice or guinea pigs. Strains can be grouped according to their disease producing capabilities in mice, guinea pigs and pigeons.

The organisms can be propagated in cultures of vertebrate tissues, and some strains produce destruction of host cells after serial passage.

All strains can be preserved indefinitely after propagation in chicken embryos by storing infected yolk sacs at $-70^{\circ} \mathrm{C}$; however, the large amorphous form of the organism which develops in the early stages of multiplication is inactivated by freezing.

\section{Key to the species of Chlamydia}

I. Intracytoplasmic microcolony is rigid and compact ranging from $2-10 \mu$ in diameter. The plaque contains glycogen detectable by staining with iodine. Growth in the yolk sac of the chicken embryo is inhibited by sodium sulfadiazine ( $1 \mathrm{mg}$ per embryo). . . . . . .

Chlamydia trachomatis (Busacca) Rake

II. Int racytoplasmic microcolony is nonrigid, irregular in shape and up to $12 \mu$ wide. The microcolony does not contain glycogen detectable by staining with iodine. Growth in the yolk sac of the chicken embryo is not inhibited by sodium sulfadiazine ( $1 \mathrm{mg}$ per embryo).

Chlamydia psittaci (Lillie) comb. nov. 


\section{Tests for the Identification and Differentiation of Chlamydiae}

New isolants of chlamydiae can be conclusively identified as Chlamydia trachomatis or Chlamydia psittaci by three tests. These are:

(1) Identification of the organisms as members of the genus Chlamydia.

A pure culture of the organisms which have been shown to be unable to colonize on lifeless bacteriologic media, e.g., blood agar, is propagated in the yolk sac of chicken embryos at appropriate incubation temperatures $\left(35-37^{\circ} \mathrm{C}\right.$ for human urogenital tract strains; $37-39^{\circ} \mathrm{C}$ for strains from animals with normal body temperatures that are higher than $37^{\circ} \mathrm{C}$ ). At the time of death or obvious retaraation of growth of infected embryos, the yolk sacs are removed, triturated with sand and a buffered diluent ( $\mathrm{pH} 7.0$ ) to make a 20 to $30 \%$ suspension. The suspension is boiled for 30 minutes, cooled, and aqueous $5 \%$ phenol is added to make a final concentration of $0.5 \%$ phenol. One day later, the suspension is titrated in a complement fixation test against a constant dilution of serum previously shown to contain 8 complement fixing units of chlamydial group antibodies per unit volume. The boiled and phenolized suspension is also titrated against serum previously shown not to contain such antibodies. Fixation of complement at dilutions of antigen beyond any anticomplementary level is conclusive evidence that the yolk sacs contained chlamydial organisms. Usually a minimum of 10,000 organisms is sufficient to produce complete fixation of two exact units of complement in the presence of one CF unit of antibody.

Antigens prepared by boiling and phenolizing chlamydial organisms grown in cultures of vertebrate tissues also may be used in similar tests for detection of the chlamydial group antigen, but such antigens are usually of lowe $r$ titer.

(2) Test for the presence of glycogen in intracytoplasmic microcolonies.

The chlamydiae are propagated in cultures of vertebrate tissues. The tissue cultures are examined microscopically at 1,2 and 3 days after inoculation to ascertain the presence of intracytoplasmic clusters of chlamydiae or microcolonies. 
The formation of glycogen by the microcolony is a transient phenomenon that occurs from the first through the third day of growth. During this period, infected tissue cells growing on cover slips are removed intact and fixed in absolute methyl alcohol for a minimum of four hours. The coverslips are then immersed in a $1: 1$ mixture of $5.0 \%$ iodine in $100 \%$ ethyl alcohol and aqueous $5.0 \%$ potassium iodide for four hours. The cover slips are then placed cell side down on a drop of the iodine mixture in $50 \%$ glycerin on a microscope slide. At magnifications greater than $200 \mathrm{X}$, microcolonies containing glycogen will appear brown against a light tan background. Nonglycogen forming microcolonies cannot be distinguished from other cellular material by this iodine staining method. It is important however that there be corallary proof that growth and multiplication of the organisms actually occurred in the tissue cultures before a strain of chlamydiae is declared glycogen negative. Infected tissue cultures must be incubated at temperature that is optimal for growth of the organisms.

(3) Test for susceptibility of chlamydial strains to sodium sulfadiazine.

Decimal dilutions of a suspension of chlamydiae previously propagated in 6-day-old chicken embryos are inoculated into two groups of chicken embryos. One group of the embryos is inoculated via the yolk sac route with $\mathrm{l} \mathrm{mg}$ of sodium sulfadiazine in a diluent buffered at $\mathrm{pH} 7.0$. The second group of embryos is inoculated via the yolk sac with an equal volume of the diluent without sulfadiazine. The embryos a re candled twice daily and deaths recorded for 14 days, at which time a calculation of the $\mathrm{LD}_{50}$ /unit volume of the original suspension is made for both sets of embryos. For purposes of taxonomic differentiation, susceptibility to sulfadiazine is defined as a hundredfold or more reduction in the number of embryo lethal doses $50 \%$ in a suspension of one million or more chlamydiae per unit volume titrated in chicken embryos in the presence and absence of $1 \mathrm{mg}$ of sodium sulfadiazine. This means that the $E L D_{50}$ determinations for the titrations should differ by a factor of 100 or more. 


\section{REFERENCES}

Brumpt, E. 1938. Rickettsia intracellulaire stomacale (Rickettsia culicis n.sp.) de Culex fatigans. Ann. de Parasitologie 16:153-158.

Busacca, A. 1935. Un germe aux caracteres de rickettsies (Rickettsia trachomae) dans les tissus trachomateux. Arch. Ophthal., Paris 52:567-572.

Dunlop, E.M. C., I. A. Harper, M. Khalaf al-Hussaini, J. A. Garland, J.D. Treharne, D. J. M. Wright, and B. R. Jones. 1966. Relation of tric agent to "non-specific" genital infection. Brit. J. Ven. Dis. 42:77-87.

Foley, H. and L. Parrot. 1937. Sur la Rickettsia du trachome. C. R. Soc. Biol. (Paris) 124:230-232.

Fraser, C.E.O. and D. Berman. 1965. Type specific antigens in the psittacosis-lymphogranuloma venereum group of organisms. J. Bact: 89:943-948.

Gerloff, R.K. , D. B. Ritter, and R. O. Watson. 1966. DNA homology between the meningopneumonitis agent and related microorganisms. J. Inf. Dis. 116:197-202.

Gordon, F. B. and A. L. Quan. 1965. Occurrence of glycogen in inclusions of the psittacosis-lymphogranuloma venereum-trachoma agents. J. Inf. Dis. 115:186-196.

Jones, H., G. Rake and B. Stearns. 1945. Studies on lymphogranuloma venereum. III. The action of the sulfonamides on the agent of lymphogranuloma venereum. J. Inf. Dis. 76:55-69.

Levaditi, J.C., F. Roger, and P. Destombes. 1964. Tentative de classification des Chlamydiaceae (Rake, 1955) tenante compte de leurs affinites tissulaires et de leur epidemiologie. Ann. Inst. Pasteur 107:656-662.

Levinthal, A. 1930. Die Aetiologie der Psitakos. 1st Intern. Congr. Microbiol. Paris 1:523-528.

Lillie, R. D. 1930. Psittacosis-rickettsia-like inclusions in man and in experimental animals. Publ. Hlth. Rep. Wash. 45:773-778.

Lin, H. and J.W. Moulder. 1966. Patterns of response to sulfadiazine, $D$-cycloserine and $D$-alanine in members of the psittacosis group. J. Inf. Dis. 116:372-376.

Meyer, K. F. 1953. Psittacosis Group. Ann. N. Y. Acad. Sci. 56:545-556.

Moulder, J.W. 1964. The psittacosis group as bacteria. J. Wiley and Sons, New York. pp. 1-95.

- 1966. The relation of the psittacosis group (Chlamydiae) to bacteria and viruses. Ann. Rev. Microbiol. 20: 107-130. 
Moshkovsky, S. D. 1945. The cytotropic agents of infections and the position of the rickettsiae in the system of Chlamydozoa. (in Russian) Advances in Modern Biology (in Russian). Uspekhi Souremennoi Biol. 19:1-44.

Page, L. A. 1966. Revision of the family Chlamydiaceae Rake (Rickettsiales); unification of the psittacosis lymphogranuloma venereum-trachoma group of organisms in the genus Chlamydia Jones, Rake and Stearns, 1945. Int. J. Syst. Bact. 16:223-252.

- 1967. Comparison of "pathotypes" among chlamydial (psittacosis) strains recovered from diseased birds and mammals. Bull. Wildl. Dis. Assoc. 3:166-175.

Rake. G. 1948. Family Chlamydiaceae Moshkovsky. In: Bergey's Manual of Determinative Bacteriology. 6th ed. pp. 1119-1120. Williams and Wilkins Co., Baltimore, Md. - 1957. Family II. Chlamydiaceae Rake fam. nov. In: Bergey's Manual of Determinative Bacteriology, 7th ed. pp. 957-968. Williams and Wilkins, Baltimore, Md.

Ruske, H. and K. Poppe. 1947. Elektronen mikroskopis che Untersuchungen zur Morphologie der Seiffertschen Mikroorganismen und des Erregers der Lungenseuche des Rindes. Zeitschr. f. Hygiene 127:201-215.

Ryzhkov, V. L. 1950. Study on systematic of viruses. (in Russian.) Voprosy Meditsinskoü Virusol. Moskau 3:9-19.

Schachter, J. 1967. A bedsonia isolated from a patient with clinical lymphog ranuloma venereum. Am. J. Ophthomol. 63:1049-1052.

Zhdanov, V. and R.S. Korenblit. 1950. Systematics and nomenclature of viruses. Zhur. Mikrobiol. Epidemiol. Immunobiol. 9:40-44. (Report at scientific conference Ukrainian Inst. imeni Mechnikov in Kharkov 11 October 1949).

- 1953. Guide to the human and animal viruses. (in Russian) Akad. Med. Nauk. SSSR Moxcow, pp. 1-348. 